\title{
Predictive Control of a Back-to-Back NPC Converter-Based Wind Power System
}

\author{
Alejandro Calle-Prado, Student Member, IEEE, Salvador Alepuz, Senior Member, IEEE, \\ Josep Bordonau, Member, IEEE, Patricio Cortés, Member, IEEE, and Jose Rodriguez, Fellow, IEEE
}

\begin{abstract}
As wind power technology points to increase power ratings, the implementation based on a permanent-magnet synchronous generator with a full power converter is expanding its market share. Multilevel converters, as for example, neutralpoint clamped converters, are therefore well suited for this application. Predictive current control presents similar dynamic response and reference tracking than other well-established control methods, but working at lower switching frequencies, and providing extensive flexibility to apply either on-line or off-line different control laws to the same plant. In this work, the predictive current control is applied to the both sides of the backto-back neutral-point clamped converter connecting a permanent-magnet synchronous wind power generator to the grid. Dc-link neutral-point balance is achieved by means of the predictive control algorithm, which considers the redundant switching states of the back-to-back neutral-point clamped converter. Reduced number of commutations, current spectrum control, and compliance with the low voltage ride-through requirement are carried out with the predictive control. The obtained experimental results confirm the suitability of the proposed control approach.
\end{abstract}

Index Terms - Wind energy, permanent-magnet synchronous generator, reactive support, voltage unbalance, predictive control, low-voltage ride-through.

\section{INTRODUCTION}

$\mathrm{W}$ IND power generation is nowadays a consolidated system for generating electrical energy, with significant penetration. At the end of 2014, the global installed wind

Manuscript received May 30, 2015; revised September 17, 2015 and November 27, 2015; accepted December 26, 2015.

Copyright (C) 2016 IEEE. Personal use of this material is permitted. However, permission to use this material for any other purposes must be obtained from the IEEE by sending a request to pubs-permissions@ieee.org

The authors acknowledge the support of the Ministerio de Economia y Competitividad, Spain, under grant DPI2014-54435-P, Universidad Andrés Bello, the Advanced Center for Electric and Electronic Engineering (AC3E), and the Chilean National Fund for Scientific and Technological Development (FONDECYT), under grant No. 1150829.

A. Calle-Prado and J. Bordonau are with the Department of Electronic Engineering, Universitat Politècnica de Catalunya, 08028 Barcelona, Spain (email: alejandro.calle@upc.edu; josep.bordonau@upc.edu).

S. Alepuz is with the Mataro School of Technology (Tecnocampus Mataró-Maresme), Universitat Pompeu Fabra, 08302 Mataro (Barcelona), Spain (email: dr.salvador.alepuz@ieee.org).

P. Cortes is with REFU Elektronik, Pfulligen, Germany (email: Patricio.Cortes.Estay@refu-elektronik.de).

J. Rodriguez is with Universidad Andrés Bello, Santiago, Chile (email: jose.rodriguez@unab.cl). power capacity reached about $394 \mathrm{GW}$ [1]. For instance, in Spain, the wind power penetration was $20.4 \%$ in 2014 [2].

The Doubly-Fed Induction Generator (DFIG) [3] has been traditionally preferred to implement the Wind Energy Conversion Systems (WECS), because it provides good performance and variable speed operation with a converter designed for about the $30 \%$ of the machine nominal power [4]. However, current trend points to an implementation based on a Permanent-Magnet Synchronous Generator (PMSG) with a full power converter [4]-[6]. Although this configuration has higher converter losses than DFIG, it presents some interesting properties: gearbox can be avoided in direct-drive PMSG; no slip rings are required; provides extended speed operating range; provides full decoupling between the generator and the grid, which results in higher power capture at different wind speeds and enhanced capability to meet the grid connection requirements (GCR) enforced by the transmission and distribution system operators (TSO and DSO) [7]; and allows dc voltage power transmission [8]. These properties can make it preferable than DFIG, because reliability and power ratings are increased, which are key issues, particularly with larger power and size off-shore wind turbines [9].

The low-voltage two-level Voltage-Source Converter (VSC) is the most used topology in WECS [10], both for DFIG and for full-power converters. However, current-source converters [11] and multilevel topologies [12], [13] can be better suited than conventional VSCs for higher power levels, considering that WECS currently tend to increase their power rating [4], mostly because of the proliferation of larger offshore wind turbines [9]. Among the multilevel topologies, the Neutral-Point Clamped (NPC) converter [14] is more suitable for back-to-back applications, presents a simpler structure [12], and has reached a degree of maturity that makes it proper for many applications [13], including WECS [4], [15]-[17]. In comparison to conventional two-level VSC, the NPC presents the following advantages [18]: reduced voltage ratings for the switches, good harmonic spectrum (makes possible the use of smaller and cheaper filters) and good dynamic response. However, the number of devices is twice as for conventional VSC, increasing the switching strategy complexity. A drawback of the NPC is that the dc-link neutral point voltage regulation is required. If no regulation is made, unbalance of this voltage may lead to device failing and harmonic contents increase. However, it is not actually a problem, because there are switching strategies that assure the dc-link voltage balance under any condition. 


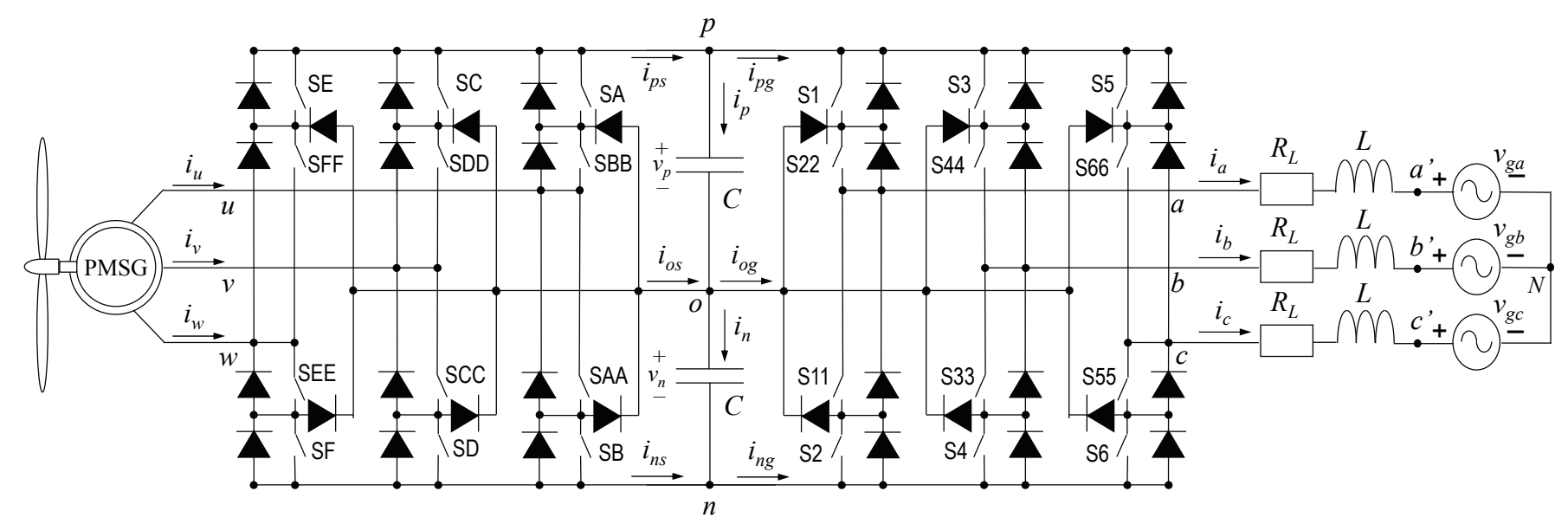

Fig. 1. PMSG connected to the grid through a back-to-back NPC converter and an inductive filter.

There are several control approaches in the literature for the PMSG connected to the grid with a back-to-back VSC [19], [20] and NPC [16], [21], most of them based on the conventional control theory and symmetrical components. The decoupling introduced by the dc-link in the back-to-back configuration makes easier to analyze separately the generator- and grid-side converters. Therefore, many contributions are focused in only one side of the topology [15], [22]-[25]. However, the predictive control applied to the complete back-to-back NPC-based WECS is hardly covered by the current literature in the field [26].

The Model Predictive Control (MPC) [27] is based on the dynamic model of the plant to be controlled within a time horizon. Finite Control Set MPC (FCS-MPC) [23], [28]-[30] is a subset of the MPC, particularly interesting as it takes advantage of the bounded number of switching states of the converter for solving the optimization problem from a discrete model of the system. The switching state that minimizes a user-defined quality function is directly applied to the power converter. Therefore, no modulator is needed.

The inclusion of nonlinearities and constraints of the system is another advantage of the FCS-MPC, as they can be included in the control law straightforward [28], [31]-[33]. Moreover, it provides a great flexibility in controlling the plant, as the control objectives can be modified by changing the quality function online. However, the accuracy of the FCS-MPC is affected by the precision at estimating the values for the system parameters [28].

In this work, predictive current control is applied to both generator- and grid-side NPC converters in the WECS shown in Fig. 1. This control approach seems not to be covered by the previous literature in the field. Under normal system operation, in steady-state and transient operation, different quality functions are applied to reduce the number of commutations, or to control the grid current spectrum. Under grid perturbation operation, the proposed controller provides balanced grid currents and proper active and reactive power regulation, allowing to fully meet the low voltage ride-through (LVRT) requirement demanded by the GCR, with energy storage in the inertia [21]. Dc-link neutral-point voltage balance is also achieved by means of the predictive control algorithm, which considers the redundant switching states of both NPCs. Two external loops with PI controllers are in charge of the PMSG speed control and dc-link voltage control.

Notice that some preliminary simulation results have been published by the authors in [26], but the previous paper does not include commutations reduction, grid current spectrum control and experimental results.

The paper is organized as follows: Section II describes the model of the system. Section III presents the predictive control implemented in this work. The experimental results that verify the suitability of the proposed control scheme are found in Section IV. Some conclusions are formulated in Section V.

\section{MOdEL OF THE SySTEM.}

The proposed control block diagram for the WECS in Fig. 1 is depicted in Fig. 2. The predictive controller is in charge of controlling both NPC three-phase currents and the dc-link voltage balance. Proportional-Integral (PI) controllers have been designed for controlling the dc-link voltage and the generator speed, which is the conventional control approach [27], [34], [35].

Notice that a predictive controller could also be used for regulating the dc-link [36]. However, the use of a predictive controller to regulate the dc-link voltage seems not providing any significant advantage in comparison with a conventional PI controller, as deduced from [33]. For the generator speed controller, predictive speed control is currently under development [27]. Therefore, a conventional control approach for the dc-link voltage and the generator speed has been selected in this work.

The continuous-time equations of the system are discretized by using a forward Euler approach, because the inherent discrete-time nature of predictive control. To do that, over a sampling period $\left(T_{s}\right)$, the derivative forms $d i(t) / d t$ and $d v(t) / d t$ are approximated by (1).

$$
\frac{d i(t)}{d t} \approx \frac{i(k+1)-i(k)}{T_{s}} ; \frac{d v(t)}{d t} \approx \frac{v(k+1)-v(k)}{T_{s}}
$$




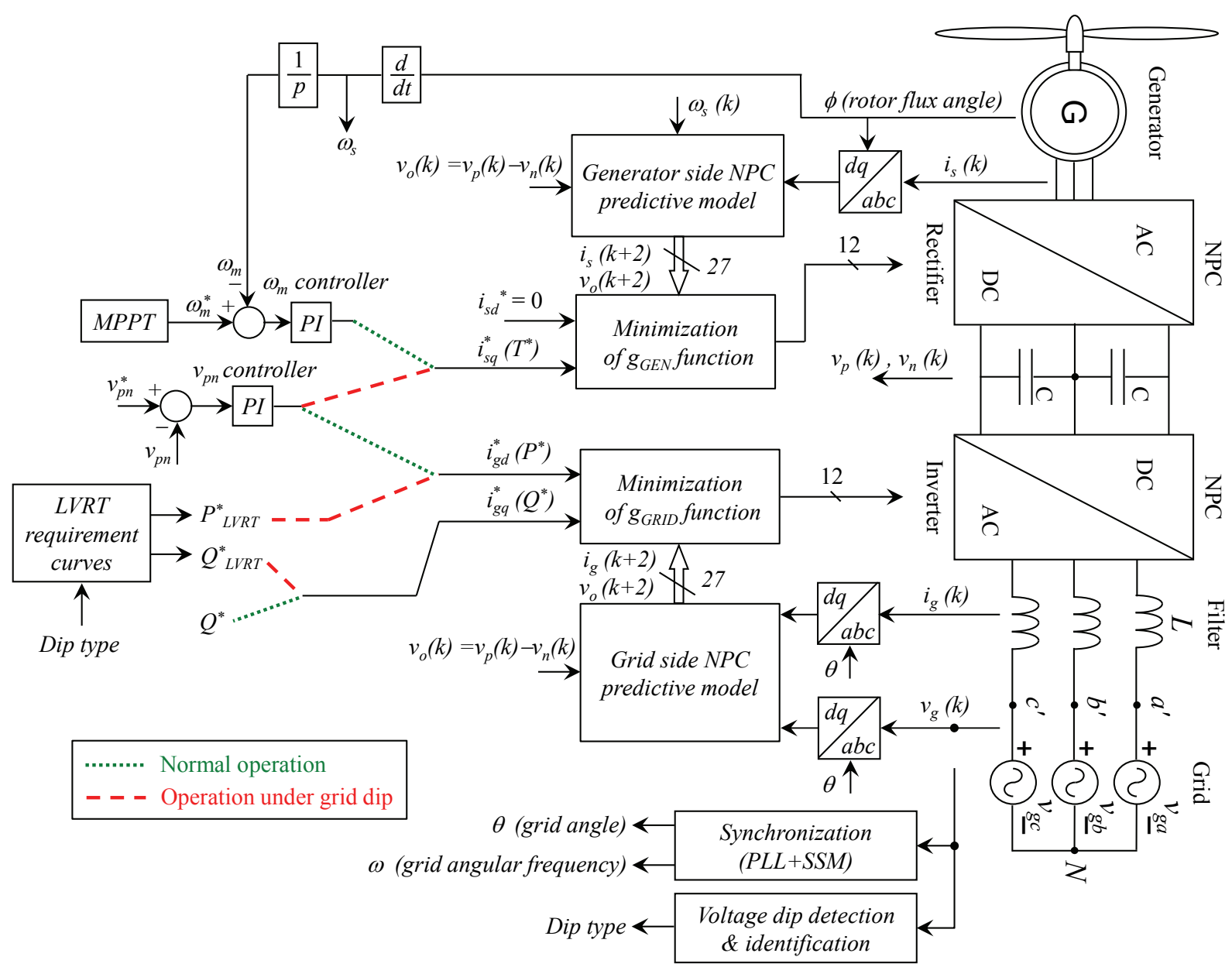

Fig. 2. Proposed control block diagram for the WECS in Fig. 1, valid both for normal operation and for LVRT compliance.

\section{A. Switching model of the NPC.}

The voltages generated by the NPC at the converter terminals are shown in (2) and (3) for the generator- and gridside NPCs, respectively

$$
\begin{array}{ll}
v_{x o}=S_{x p} \cdot v_{p}+S_{x o} \cdot 0-S_{x n} \cdot v_{n} & \text { where } x=\{u, v, w\} \\
v_{y o}=S_{y p} \cdot v_{p}+S_{y o} \cdot 0-S_{y n} \cdot v_{n} & \text { where } y=\{a, b, c\}
\end{array}
$$

where the switching functions are defined in (4) and (5) for the generator- and grid-side NPCs, respectively

$$
\begin{aligned}
& \begin{array}{l}
S_{x j}=1 \text { if } x \text { connected to } j \\
S_{x j}=0 \text { if } x \text { not connected to } j
\end{array} \text { where }\left\{\begin{array}{l}
x=\{u, v, w\} \\
j=\{p, o, n\}
\end{array}\right. \\
& S_{y j}=1 \text { if } y \text { connected to } j \\
& S_{y j}=0 \text { if } y \text { not connected to } \\
& \text { where }\left\{\begin{array}{l}
y=\{a, b, c\} \\
j=\{p, o, n\}
\end{array}\right.
\end{aligned}
$$

The NPC has 27 possible switching states with 19 voltage vectors [37], as shown in Fig. 3.

\section{B. Model of the generator side.}

For the generator side, the equations of the PMSG are shown in (6)-(8). Electrical and torque equations are expressed in the rotative $d q$ frame, with the $q$ axis aligned with the rotor flux [38]

$$
T_{e}=p \cdot \psi_{r} \cdot i_{s q}
$$

$$
\begin{aligned}
& T_{m}-T_{e}=J \frac{d}{d t} \omega_{m}+b \omega_{m} \\
& v_{s d}=R_{s} i_{s d}+L_{s} \frac{d}{d t} i_{s d}-\omega_{s} L_{s} i_{s q} \\
& v_{s q}=R_{s} i_{s q}+L_{s} \frac{d}{d t} i_{s q}+\omega_{s} L_{s} i_{s d}+\omega_{s} \psi_{r}
\end{aligned}
$$

where $\left(v_{s d}, v_{s q}\right)$ is the stator voltage $v_{s}$ in the $d q$ frame; $\left(i_{s d}, i_{s q}\right)$ the stator current $i_{s}$ in the $d q$ frame; $L_{s}$ the stator inductance; $R_{s}$ the stator resistance; $\omega_{s}$ the rotor flux electrical speed, $\psi_{r}$ the rotor flux; $T_{e}$ the electromagnetic torque; $p$ the machine pole pairs; $T_{m}$ the mechanical torque; $J$ the moment of inertia (turbine-generator); $\omega_{m}=\omega_{s} / p$ the shaft mechanical speed; $b$ the friction coefficient.

To align the $q$ axis with the rotor flux, the rotor flux angle $\phi$, see Fig. 2, is obtained with an encoder. The rotor flux $\psi_{r}$ has been previously calculated by testing the machine with no electrical load $\left(i_{s}=0\right)$ and measuring both the speed and the stator voltage, which in this case is equal to the electromotive force $\left(E=\omega_{s} \psi_{r}\right)$, as deduced from (8).

Discretizing the electrical equations (8), it results

$$
\begin{aligned}
& i_{s d}(k+1)=\left(1-\frac{R_{s} T_{s}}{L_{s}}\right) i_{s d}(k)+\omega_{s} T_{s} i_{s q}(k)+\left(\frac{T_{s}}{L_{s}}\right) v_{s d}(k) \\
& i_{s q}(k+1)=\left(1-\frac{R_{s} T_{s}}{L_{s}}\right) i_{s q}(k)-\omega_{s} T_{s} i_{s d}(k)+\left(\frac{T_{s}}{L}\right)\left(v_{s q}(k)-E(k)\right)
\end{aligned}
$$




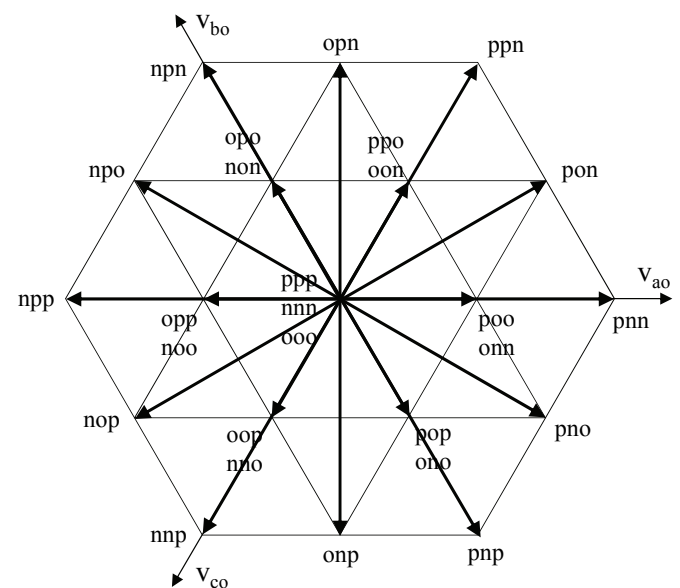

Fig. 3.27 switching states and 19 voltage vectors of a NPC converter.

Equation (9) in the $d q$ frame is used to obtain predictions for the future value of the generator current $i_{s}(k+1)$, considering all possible voltage vectors $v_{s}(k)$ generated by the generator-side NPC, shown in Fig. 3, the measured generator current $i_{s}(k)$ and the generator electromotive force $E(k)$.

\section{Model of the grid side.}

The model for the grid-side converter in the $d q$ frame is [39]

$$
\begin{aligned}
& v_{N P C d}=R_{L} i_{g d}+L \frac{d}{d t} i_{g d}-\omega L i_{g q}+v_{g d} \\
& v_{N P C q}=R_{L} i_{g q}+L \frac{d}{d t} i_{g q}+\omega L i_{g d}+v_{g q}
\end{aligned}
$$

where $\left(v_{N P C d}, v_{N P C q}\right)$ is the NPC output voltage $v_{N P C}$ in the $d q$ frame; $\left(v_{g d}, v_{g q}\right)$ is the grid voltage $v_{g}$ in the $d q$ frame; $\left(i_{g d}, i_{g q}\right)$ the grid current $i_{g}$ in the $d q$ frame; $L$ the filter inductance; $R_{L}$ the filter resistance; $\omega$ the grid angular frequency. The discretized equations are

$$
\begin{aligned}
& i_{g d}(k+1)=\left(1-\frac{R_{L} T_{s}}{L}\right) i_{g d}(k)+\omega T_{s} i_{g q}(k)+\left(\frac{T_{s}}{L}\right)\left(v_{N P C d}(k)-v_{g d}(k)\right) \\
& i_{g q}(k+1)=\left(1-\frac{R_{L} T_{s}}{L}\right) i_{g q}(k)-\omega T_{s} i_{g d}(k)+\left(\frac{T_{s}}{L}\right)\left(v_{N P C q}(k)-v_{g q}(k)\right)
\end{aligned}
$$

Equation (11) in the $d q$ frame is used to obtain predictions for the future value of the grid current $i_{\text {grid }}(k+1)$, considering all possible voltage vectors $v_{N P C}(k)$ generated by the grid-side NPC, see Fig. 3, the measured grid current $i_{\text {grid }}(k)$ and grid voltage $v_{\text {grid }}(k)$.

\section{Model of the dc-link.}

From Fig. 1, the dc-link voltage $v_{p n}$ and the voltage unbalance $v_{o}$ is defined as

$$
v_{p n}=v_{p}+v_{n} \quad ; \quad v_{o}=v_{p}-v_{n}
$$

The model for the dc-link is

$$
\frac{d}{d t} v_{p}=\frac{1}{C} i_{p} \quad ; \quad \frac{d}{d t} v_{n}=\frac{1}{C} i_{n}
$$

where $i_{p}, i_{n}$ are the currents through each dc-link capacitor; $v_{p}$ , $v_{n}$ the dc-link capacitor voltages; $C$ the dc-link capacitance value. However, for the predictive controller, only the dc-link voltage unbalance is considered. Hence, by using (12), (13) and deducing from Fig. 1 that $i_{p g}+i_{o g}+i_{n g}=0$ and $i_{p s}+i_{o s}+i_{n s}=0$, it yields (14) and, once discretized, results in (15).

$$
\begin{gathered}
\frac{d}{d t} v_{o}=\frac{1}{C}\left(i_{o g}-i_{o s}\right) \\
v_{o}(k+1)=v_{o}(k)+\frac{T_{s}}{C}\left(i_{o g}(k)-i_{o s}(k)\right)
\end{gathered}
$$

The current through the dc-link midpoint $i_{o s}$ is obtained (16), from the present stator currents and the midpoint switching function (4) of the generator-side NPC. With the same procedure for the grid-side NPC, the current through the dc-link midpoint $i_{o g}$ is obtained by using (17) and (5). Note that the calculation of $v_{o}(k+1)$ is only needed if a current is drawn from the midpoint of the dc-link.

$$
\begin{aligned}
& i_{o s}(k)=S_{u o}(k) \cdot i_{u}(k)+S_{v o}(k) \cdot i_{v}(k)+S_{\mathrm{wo}}(k) \cdot i_{w}(k) \\
& i_{o g}(k)=S_{a o}(k) \cdot i_{a}(k)+S_{b o}(k) \cdot i_{b}(k)+S_{\mathrm{co}}(k) \cdot i_{c}(k)
\end{aligned}
$$

Equation (15) can be used to obtain predictions for the future value of the dc-link voltage unbalance $v_{o}(k+1)$ based on measured voltage unbalance $v_{o}(k)=v_{p}(k)-v_{n}(k)$ and the present midpoint currents $i_{o s}(k), i_{o g}(k)$, which depend on the measured generator currents $i_{u}(k), i_{v}(k), i_{w}(k)$, the present applied generator-side NPC midpoint switching function $S_{u o}(k), S_{v o}(k)$ , $S_{w o}(k)$, the measured grid currents $i_{a}(k), i_{b}(k), i_{c}(k)$ and the present applied grid-side NPC midpoint switching function $S_{a o}(k), S_{b o}(k), S_{c o}(k)$. Therefore, there is no need to measure the dc-link capacitor currents $i_{p}(k), i_{n}(k)$.

\section{E. Delay compensation.}

The implementation of FCS-MPC requires to consider the effect of the delay in the actuation due to the time needed for the measurements through analog-to-digital converters and algorithm calculations. Therefore, the discrete-time equations of the model (9), (11) and (15) are shifted one step forward in time to consider this time delay [40], resulting in (18)-(20).

The future generator currents $i_{s}(k+1)$ in (18) can be estimated from (9). It is assumed $E(k+1) \approx E(k)$ for future value of the electromotive force in (18), because generator speed does not vary significantly during $T_{s}$.

The future grid currents $i_{g}(k+1)$ in (19) can be estimated from (11). For the future value of the grid voltage vector $v_{g}(k+1)$, it is possible to consider $v_{g}(k+1)=v_{g}(k)$, as $d q$ components of the grid voltage are expected to keep constant.

The future value of the dc-link voltage unbalance $v_{o}(k+1)$ in (20) is obtained from (15).

$$
\begin{aligned}
& i_{s d}(k+2)=\left(1-\frac{R_{s} T_{s}}{L_{s}}\right) i_{s d}(k+1)+\omega_{s} T_{s} i_{s q}(k+1)+ \\
& +\left(\frac{T_{s}}{L_{s}}\right) v_{s d}(k+1) \\
& i_{s q}(k+2)=\left(1-\frac{R_{s} T_{s}}{L_{s}}\right) i_{s q}(k+1)-\omega_{s} T_{s} i_{s d}(k+1)+ \\
& +\left(\frac{T_{s}}{L}\right)\left(v_{s q}(k+1)-E(k+1)\right)
\end{aligned}
$$




$$
\begin{aligned}
& i_{g d}(k+2)=\left(1-\frac{R_{L} T_{s}}{L}\right) i_{g d}(k+1)+\omega T_{s} i_{g q}(k+1)+ \\
& +\left(\frac{T_{s}}{L}\right)\left(v_{N P C d}(k+1)-v_{g d}(k+1)\right) \\
& i_{g q}(k+2)=\left(1-\frac{R_{L} T_{s}}{L}\right) i_{g q}(k+1)-\omega T_{s} i_{g d}(k+1)+ \\
& +\left(\frac{T_{s}}{L}\right)\left(v_{N P C q}(k+1)-v_{g q}(k+1)\right) \\
& v_{o}(k+2)=v_{o}(k+1)+\frac{T_{s}}{C}\left(i_{o g}(k+1)-i_{o s}(k+1)\right)
\end{aligned}
$$

\section{CONTROL SYSTEM DESCRIPTION.}

\section{A. Normal operation.}

In normal operation, for the generator-side converter, the speed reference is given by a maximum power point tracking (MPPT) algorithm, to extract the maximum amount of power from the wind. The MPPT algorithm has not been considered in this work. The speed controller, implemented with a conventional PI regulator, provides the electromagnetic torque reference, i.e. the $q$ axis generator current reference $\left(i_{s q}{ }^{*}\right)$, to be extracted from the generator, which is carried out by the generator-side predictive current controller. The $d$ axis generator current reference $\left(i_{s d}{ }^{*}\right)$ is set to 0 [38]. In steadystate, the electromagnetic torque matches the mechanical torque and the generator speed equals the speed reference. The active power drawn from the generator is delivered to the dclink. The dc-link PI regulator, in order to keep the dc-link voltage to the reference, gives the $d$ axis grid current reference $\left(i_{g d}{ }^{*}\right)$. Therefore, the same amount of active power drawn from the generator is delivered to the grid, in case of having an ideal loss-free system. On the other hand, the reactive power given/absorbed to/from the grid can be regulated by means of the $q$ axis grid current $\left(i_{g q}{ }^{*}\right)$, independently from the active power regulation. The grid current is controlled by the gridside predictive current controller. It can be observed that the dc-link voltage unbalance is controlled by the predictive controllers at both sides, as detailed below.

\section{B. Control to meet the LVRT requirements.}

As shown in Fig. 2, when a grid dip appears, the references of the active and reactive power to inject into the grid are switched as they are function of the specific voltage dip type and depth, accordingly with the LVRT requirements [7], shown in Fig. 4 and Fig. 5.

When a voltage sag is present in the grid, the WECS must remain connected to the grid unless the line voltage is located under the limit line in Fig. 4. Simultaneously, the system needs to support the network by delivering an amount of reactive current. The percentage of delivered reactive current, shown in Fig. 5, is proportional to the voltage dip depth, the system rated current and the amount of reactive current delivered to the grid before the instant the voltage sag appears. After fault clearance, there is a need to keep supporting the voltage by injecting reactive current for a time, $500 \mathrm{~ms}$, and the active power must recover to its original value with

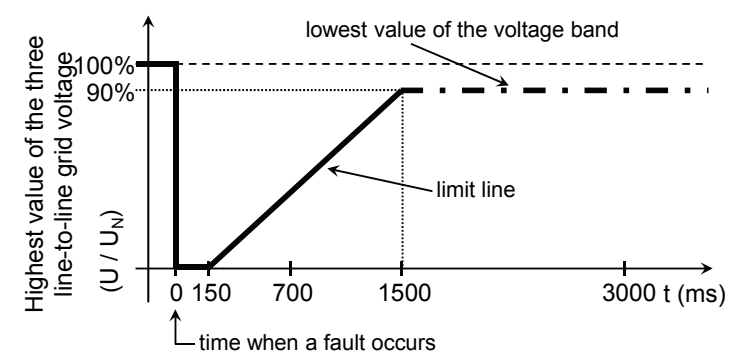

Fig. 4. EON grid code: voltage limit curve to allow WECS disconnection [7].

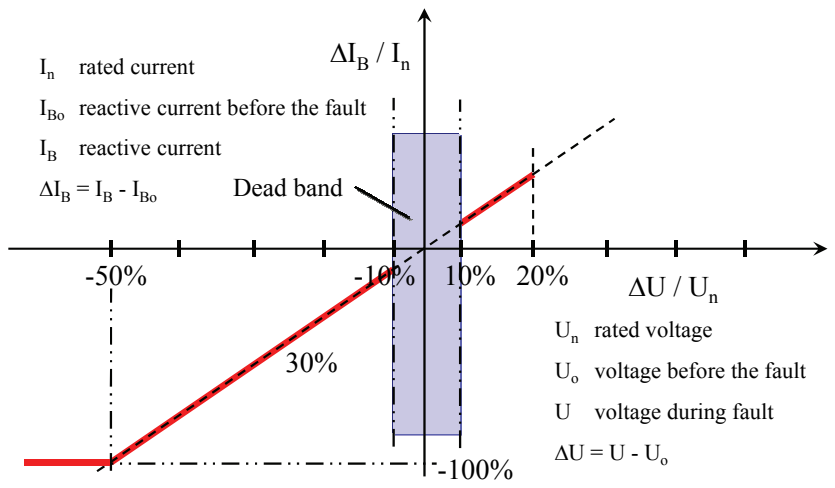

Fig. 5. EON grid code: reactive current to be delivered to the grid under a voltage dip [7].

minimum gradient of $20 \%$ of the rated power per second [7].

A voltage dip detection and identification [41]-[43] is needed but, for the sake of simplicity, it has not been implemented in this work, because the voltage dip type and depth is set by the user at the experimental setup. As the active power extracted from the turbine does not change, an active power mismatch appears in the system. With the control block diagram in Fig. 2, the active power surplus present during the dip is stored in the inertia of the turbine-generator mechanical system [21]. The dc-link voltage is controlled in this case by the generator-side converter and the generator speed is not controlled, but the speed increase is small and acceptable in generators with high inertia [21], [44].

In this work, the $a b c$ grid current references have been set to be symmetrical and balanced at all-time [15], i.e., the currents only present positive sequence, with the negative sequence equal to zero. However, other different strategies to generate the grid current reference to meet the LVRT requirement could be considered [45]. Thus, the grid current reference requires to be synchronized with the positive sequence of the grid voltage.

The angle of the positive sequence of the grid voltage $(\theta)$ is obtained with the synchronization block [46] shown in Fig. 2, which contains a Phase-Locked Loop (PLL) working with the Delayed Signal Cancellation (DSC) sequence separation method (SSM). This synchronization block guarantees angle precision under both symmetrical and asymmetrical grid faults [46], [47]. With the proposed control approach, a SSM is not required for control purposes, since symmetrical components are needed only for the synchronization task.

\section{Predictive control description.}

The predictive control is in charge of the generator currents, the all-time balanced grid currents, and the dc-link voltage 
balance. These control objectives are accomplished by minimizing a given quality function, which considers the tracking of the current references and the dc-link voltage unbalance. Other control objectives are discussed below.

By using the discrete-time model of the system, the predictive control algorithm calculates the predictions of the variables to control at the instant $k+2$ for all the possible switching states of the system, and then the quality function is evaluated for all the switching states. The switching state which minimizes the quality function is selected to be applied to the system at the beginning of the next sampling period.

The three-phase currents for each side in the system of Fig. 1 are decoupled from the other side, as deduced from (18) and (19). That is, the generator currents only depend on the generator-side NPC voltage vectors, do not depend on the grid-side NPC voltage vectors, and vice versa. Therefore, the quality function has to be evaluated 19 times for each side, as there are 19 different voltage vectors for a NPC converter. Redundant switching states with the same voltage vector give the same current prediction.

However, notice that the switching states of both converters concurrently influence in the calculation of the voltage unbalance $v_{o}(k+2)$ in (20). Therefore, a NPC has 27 different switching states, there are $27^{2}=729$ different possible combinations for (20). As the quality function should be evaluated 729 times, the runtime of the predictive control would extend significantly and requires a too long $T_{s}$.

To avoid such a large number of calculations, in this work, each side of the system has its separate predictive controller and the current and the voltage unbalance are evaluated separately for each NPC converter, as if each NPC converter is working alone. To do that with the voltage unbalance $v_{o}(k+2)$ in (18), the current $i_{\text {og }}(k+1)$ is nullified when the calculation is done for the generator-side converter, and the current $i_{o s}(k+1)$ is nullified when the calculation is done for the grid-side converter. Therefore, only $27 \cdot 2=54$ iterations are needed.

The simulated results for both approaches are shown in Fig. 6. As expected, a smaller dc-link voltage unbalance is present when considering the switching states of both converters concurrently, Fig. 6(d)-(f), in comparison with the dc-link voltage unbalance while using two separate predictive controllers, Fig. 6(a)-(c). The current tracking performance does not deteriorate for either of these options. A sampling period of $100 \mu \mathrm{s}$ have been used for these simulations, as it is the selected sampling period for the experimental results shown in section IV. Unfortunately, the concurrent controller strategy cannot be executed in the experimental setup with the selected sampling period as its execution time is $279 \mu \mathrm{s}$, while the separate controller strategy only requires $70 \mu \mathrm{s}$. Therefore, the concurrent controller has been simulated with a sampling period of $300 \mu \mathrm{s}$, higher than the required $279 \mu \mathrm{s}$ to be executed in real-time, with results shown in Fig. 6(g)-(i). In this case, although the concurrent controller is used, because of the higher sampling period, both the dc-link voltage balance and the current performance deteriorate in comparison with the results obtained by using the separate controller strategy with a smaller sampling period shown in Fig. 6(a)-(c).
Although the selected approach does not offer the optimal switching state that minimizes the voltage unbalance when both NPCs are considered, it provides a good trade-off between accuracy and number of calculations. The simulation results shown in Fig. 6 as well as the good experimental results shown in Section IV validate this approach.

For the generator-side predictive controller, the future value of the generator current $i_{s}(k+2)$ and dc-link voltage unbalance $v_{o}(k+2)$ are predicted for the 27 switching states generated by the generator-side NPC, by using (18) and (20). The estimated values at the instant $k+1$, needed for the predictions at the instant $k+2$, are given by (9) and (15). It is worth to recall that $i_{\text {og }}(k)=0$ in (15) and $i_{\text {og }}(k+1)=0$ in (20) for the generator side calculation. The proposed quality function for the generator side NPC $g_{S}$ to be evaluated for all the switching states is shown in (21).

$$
\begin{aligned}
g_{S}= & \left(i_{s d}^{*}(k+2)-i_{s d}(k+2)\right)^{2}+\left(i_{s q}^{*}(k+2)-i_{s q}(k+2)\right)^{2}+ \\
& +\lambda_{o S}\left(v_{o}(k+2)\right)^{2}+\lambda_{c S} \cdot n_{S}^{2}
\end{aligned}
$$

The first two terms in the quality function $g_{S}$ (21) are dedicated to achieve reference tracking, quantifying the difference between the reference current $i_{s}{ }^{*}$ and the current prediction $i_{s}$ on the sampling time $k+2$, for a given switching state, in the $d q$ frame.

The third and fourth terms in the quality function $g_{S}(21)$ take advantage of the redundant switching states of the NPC, from the fact that the tracking cost of the current depends only on the voltage vector selected. The variable $n_{S}$ is the number of commutations of the generator-side NPC to get to the switching state under evaluation. The redundant switching state that generates both smaller voltage unbalance and number of commutations will be preferred [32]. The factors $\lambda_{o S}$ and $\lambda_{c S}$ assign a specific weight to the voltage balance and commutation reduction terms, respectively, within the quality function $g_{S}$. A large value of $\lambda$ implies greater priority to that objective. Some guidelines for weighting factor design are found in [28].

The predictive control strategy requires an estimation of the future reference current $i_{s}{ }^{*}(k+2)$. As the control is implemented in the dq frame, it is possible to consider $i_{s}{ }^{*}(k+2)=i_{s}{ }^{*}(k)$.

For the grid side, the proposed quality function $g_{G}$ is the same as for the generator side (22). Therefore, the detailed explanation above for the generator side is also valid here. Notice that $i_{o s}(k)=0$ in $(15)$ and $i_{o s}(k+1)=0$ in (20) to do the calculations here. The variable $n_{G}$ is the number of commutations of the grid-side NPC to get to the switching state under evaluation.

$$
\begin{aligned}
g_{G}= & \left(i_{g d}^{*}(k+2)-i_{g d}(k+2)\right)^{2}+\left(i_{g q}^{*}(k+2)-i_{g q}(k+2)\right)^{2}+ \\
& +\lambda_{o G}\left(v_{o}(k+2)\right)^{2}+\lambda_{c G} \cdot n_{G}^{2}
\end{aligned}
$$

The values for $\lambda_{o S}, \lambda_{c S}, \lambda_{o G}$ and $\lambda_{c G}$ used in this work are specified in Section IV.

Finally, notice that the analysis of the stability and bounds for the controller and system presented here is beyond the scope of this work. However, the study of the stability and bounds of the FCS-MPC applied to power converters can be found in [48], [49]. 
(a)

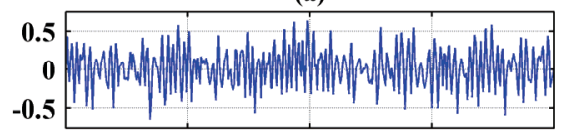

(b)

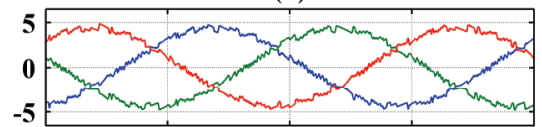

(c)

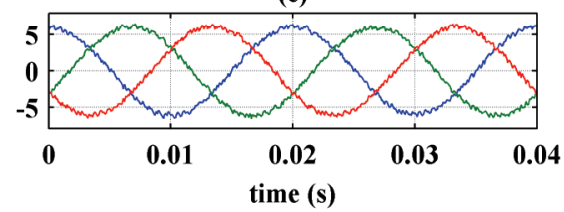

(d)

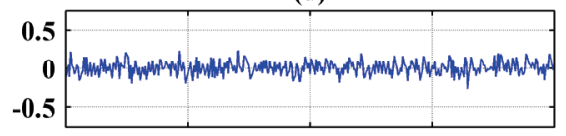

(e)

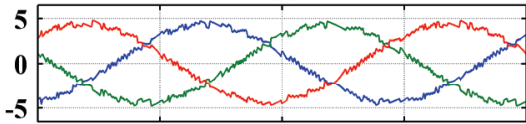

(f)

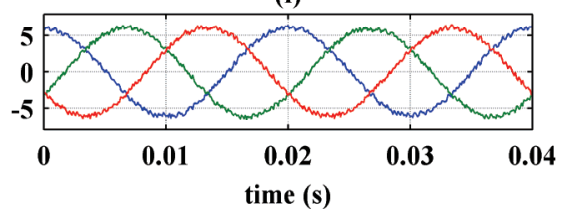

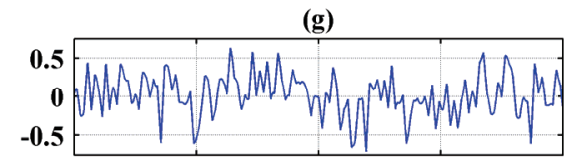

(h)

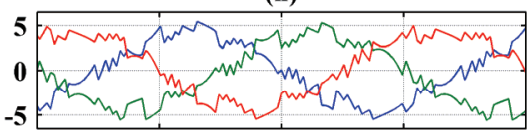

(i)

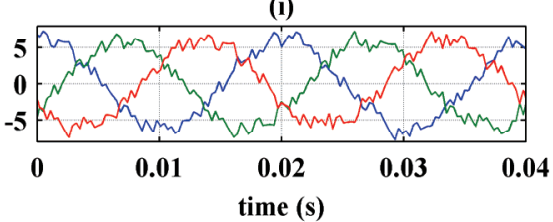

Fig. 6. Simulation results of the proposed optimization schemes for balancing the dc-link voltage. Two separate predictive controllers $\left(T_{s}=100 \mu \mathrm{s}\right)$ : (a) neutralpoint voltage balance $\left(v_{o}[\mathrm{~V}]\right)$; (b) generator-side phase currents $\left(i_{u}, i_{v}, i_{w}[\mathrm{~A}]\right)$; (c) grid-side phase currents $\left(i_{a}, i_{b}, i_{c}[\mathrm{~A}]\right)$. One concurrent predictive controller $\left(T_{s}=100 \mu \mathrm{s}\right)$ : (d) neutral-point voltage balance $\left(v_{o}[\mathrm{~V}]\right) ;(\mathrm{e})$ generator-side phase currents $\left(i_{u}, i_{v}, i_{w}[\mathrm{~A}]\right) ;(\mathrm{f})$ grid-side phase currents $\left(i_{a}, i_{b}, i_{c}[\mathrm{~A}]\right)$. One concurrent predictive controller $\left(T_{s}=300 \mu \mathrm{s}\right)$ : $(\mathrm{g})$ neutral-point voltage balance $\left(v_{o}[\mathrm{~V}]\right)$; (h) generator-side phase currents $\left(i_{u}, i_{v}, i_{w}\right.$ [A]); (i) grid-side phase currents $\left(i_{a}, i_{b}, i_{c}[\mathrm{~A}]\right)$.

\section{Restriction of the permitted future switching states.}

The number of permitted future switching states can be reduced from the total 27 to a smaller number by introducing restrictions within the predictive control algorithm.

The simplest restriction consists on restrict the commutation to only one output phase of the NPC every $T_{s}$. An additional restriction allows the commutation of each output phase only between adjacent dc voltage levels, which is interesting because the commutation between non adjacent dc-voltage levels, although admissible, is not desirable in multilevel conversion.

A simple comparison for these restrictions is shown in Table I, taking arbitrarily the present switching state 'pon' as an example. The quantity $\left(Q_{t}\right)$ of permitted future switching states reduces strongly and, hence, the number of iterations needed for the predictive control algorithm and the corresponding runtime.

Moreover, the maximum number of switches in the NPC commutating from the present state to the future state within a sampling period $\left(N_{\max } / T_{s}\right)$ also reduces strongly, thus decreasing the converter losses. Notice that the restrictions can be applied to the predictive control regardless the quality function used.

Finally, recall that the present switching state ('pon' for the example in Table I) is always a permitted future switching state. In this case, therefore, there are no commutations.

\section{E. Imposed current spectrum.}

With the typical implementation of the predictive control carried out in the previous subsections, the current spectrum is spread over a wide range of frequencies [33]. In some applications, such a spread spectrum is not desirable because it can produce oscillations and make the design of passive filters difficult [28]. Therefore, it can be useful sometimes to have a similar current spectrum as the one obtained with PWM.

To do that, the quality function should be reformulated as (23), which can be applied to one or both sides of the system in Fig. 1. This quality function works with the three-phase converter currents in the $d q$ frame, where $F(z)$ is a discretetime filter. The choice of $F(z)$ of determines the spectrum of
TABLE I

EXAMPLE OF PERMITTED FUTURE SWITCHING STATES FOR A NPC CONVERTER WITH PRESENT SWITCHING STATE 'pon'.

\begin{tabular}{|l|c|c|c|}
\hline Type of restriction & $\begin{array}{c}\text { Permitted future } \\
\text { switching states }\end{array}$ & $\boldsymbol{Q}_{\boldsymbol{t}}$ & $\boldsymbol{N}_{\boldsymbol{m a x}} / \boldsymbol{T}_{\boldsymbol{s}}$ \\
\hline No restriction & all & 27 & 16 \\
\hline $\begin{array}{l}\text { Only one phase allowed to } \\
\text { commutate (1F) every } T_{s}\end{array}$ & $\begin{array}{c}\text { oon, non } \\
\text { ppn, pnn } \\
\text { pop, poo }\end{array}$ & 7 & 4 \\
\hline $\begin{array}{l}\text { Only one phase allowed to } \\
\text { commutate (1F) \& adjacent } \\
\text { level (AL) every } T_{s}\end{array}$ & $\begin{array}{c}\text { oon } \\
\text { ppn, pnn } \\
\text { poo }\end{array}$ & 5 & 2 \\
\hline
\end{tabular}

the load currents. If $F(z)$ is chosen as a narrow band-stop filter, the current spectrum (and hence the switching frequency) will be concentrated around the center frequency of the filter, set by the user, and avoiding the presence of harmonic content over a wide range of frequencies [28], [33].

$$
\begin{aligned}
g= & \left(F\left(i_{d}^{*}(k+2)-i_{d}(k+2)\right)\right)^{2}+ \\
& +\left(F\left(i_{q}^{*}(k+2)-i_{q}(k+2)\right)\right)^{2}+\lambda_{o}\left(v_{o}(k+2)\right)^{2}
\end{aligned}
$$

\section{EXPERIMENTAL RESULTS}

The experimental results are obtained for the proposed control strategy depicted in Fig. 2 with the wind emulation platform shown in Fig. 7. The specifications for the experimental system are detailed in Table II.

The devices of the NPC converters are configurable Semikron IGBT modules SKM100 with a rated current and voltage, $\mathrm{I}_{\mathrm{C}}$ and $\mathrm{V}_{\mathrm{CES}}$, of $100 \mathrm{~A}$ and $1200 \mathrm{~V}$.

Voltage and current experimental data have been acquired through LEM LV 25-P voltage sensors and LEM LA 25-NP current sensors.

The wind is emulated with a permanent magnet synchronous motor (PMSM) driven by a PMSM power controller. The PMSM emulates the wind by providing constant torque on the shaft. Although this approach is not accurate, as the torque of a wind turbine highly depends on the 


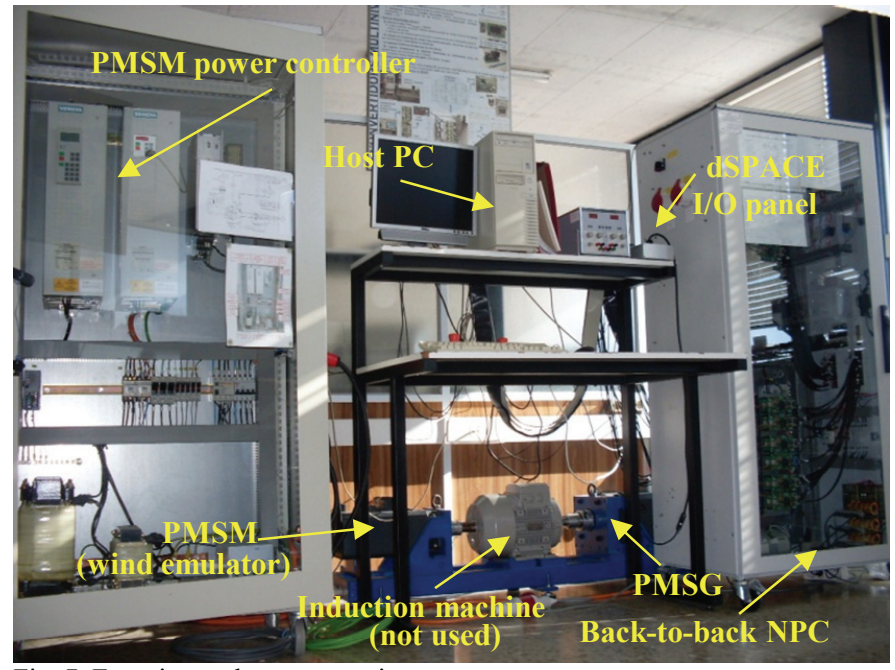

Fig. 7. Experimental setup overview.

rotational speed [22], the results are meaningful. A real wind turbine works, in steady-state, at the maximum point of the curve power-speed, due to the MPPT algorithm operation, and thus a speed increase would lead to a smaller power and torque. Hence, the assumption of constant torque made here (due to PMSM controller programming limitations) is more severe than the behavior of an actual wind turbine. The torque reference for the PMSM (i.e., wind torque) is set in the host PC by using a suitable software and can be changed online.

As shown in Fig. 7, the PMSM (wind) moves the shaft with an induction machine (not used in this work) and a PMSG connected to the back-to-back NPC and to the grid through an inductive filter, system shown in Fig. 1.

The control strategy depicted in Fig. 2 and described in Section III has been implemented using a PC-embedded PowerPC (dSPACE 1103), this fast prototyping and control platform can acquire up to 20 analog signals through different analog-to-digital converters, the results shown in this paper only require 10 converters for the sensed voltage and current signals. The calculated optimized switching states are sent every $T_{s}$ to an Altera EPF10K70 programmable logic device, which controls the commutation sequence of the 24 transistors, adds the corresponding dead times, and afterwards send the switching signals to the transistor drivers.

The experimental results presented here cover the LVRT compliance, the strategies for reducing the number of commutations and the imposed current spectrum. However, some other tests, although not reported here, have been carried out on the experimental setup with the proposed controller, such as steady-state operation, wind torque change, dc-link voltage reference step change, and shaft speed reference step change. Good current reference tracking and smaller number of commutations in comparison with PWM has been previously demonstrated [15]. In all cases, good system performance has been found.

\section{A. Results for LVRT compliance.}

A voltage dip type B [50] has been carried out in the experimental setup by switching one grid phase from its rated voltage to a smaller voltage generated by a single-phase auto-
TABLE II

EXPERIMENTAL SYSTEM AND CONTROL PARAMETERS.

\begin{tabular}{|c|c|c|c|}
\hline \multicolumn{2}{|c|}{ Parameter } & Symbol & Value \\
\hline \multicolumn{2}{|c|}{$\begin{array}{l}\text { Moment of inertia } \\
\text { (turbine-generator) }\end{array}$} & $J$ & $0.0812 \mathrm{~kg} \cdot \mathrm{m}^{2}$ \\
\hline \multicolumn{2}{|c|}{ Rotor flux } & $\psi_{r}$ & $0.382 \mathrm{~Wb}$ \\
\hline \multicolumn{2}{|c|}{ Generator pole pairs } & $p$ & 4 \\
\hline \multicolumn{2}{|c|}{ Stator inductance } & $L_{s}$ & $10 \mathrm{mH}$ \\
\hline \multicolumn{2}{|c|}{ Stator resistance } & $R_{s}$ & $0.5 \Omega$ \\
\hline \multicolumn{2}{|c|}{ Dc capacitors' capacitance } & $C$ & $2.2 \mathrm{mF}$ \\
\hline \multicolumn{2}{|c|}{ Grid filter inductance } & $L$ & $10 \mathrm{mH}$ \\
\hline \multicolumn{2}{|c|}{ Grid filter resistance } & $R$ & $0.5 \Omega$ \\
\hline \multicolumn{2}{|c|}{ Grid voltage } & $V_{\text {grid }}$ & $53 \mathrm{~V}_{\mathrm{RMS}}$ \\
\hline \multicolumn{2}{|c|}{ Grid frequency } & $f_{\text {grid }}$ & $50 \mathrm{~Hz}$ \\
\hline \multicolumn{2}{|c|}{ Mechanical torque reference } & $T_{m}{ }^{*}$ & $10 \mathrm{~N} \cdot \mathrm{m}$ \\
\hline \multicolumn{2}{|c|}{ Rotor speed reference } & $n^{*}$ & $500 \mathrm{rpm}$ \\
\hline \multicolumn{2}{|c|}{ Dc voltage reference } & $V_{p n}{ }^{*}$ & $250 \mathrm{~V}$ \\
\hline \multicolumn{2}{|c|}{ Sampling period } & $T_{s}$ & $100 \mu \mathrm{s}$ \\
\hline \multirow{2}{*}{$\begin{array}{c}\text { Dc-link voltage } \\
\text { balancing } \\
\text { weight }\end{array}$} & rectifier & $\lambda_{o S}$ & 1 \\
\hline & inverter & $\lambda_{o G}$ & 1 \\
\hline \multirow{2}{*}{$\begin{array}{l}\text { Rotor speed } \\
\text { controller }\end{array}$} & $\begin{array}{c}\text { proportional } \\
\text { constant }\end{array}$ & $K_{P R}$ & 0.05 \\
\hline & $\begin{array}{l}\text { integral } \\
\text { constant }\end{array}$ & $K_{I R}$ & 0.03 \\
\hline \multirow{2}{*}{$\begin{array}{l}\text { Dc-link voltage } \\
\text { controller }\end{array}$} & $\begin{array}{c}\text { proportional } \\
\text { constant }\end{array}$ & $K_{P D C}$ & 0.3 \\
\hline & $\begin{array}{l}\text { integral } \\
\text { constant }\end{array}$ & $K_{I D C}$ & 20 \\
\hline
\end{tabular}

transformer, using two bidirectional electronic switches.

For obtaining the results shown in Figs. 8 and 9 no commutation reduction term was taken into account so $\lambda_{c S}$ in (21) and $\lambda_{c G}$ in (22) are set to 0.

Fig. 8(a) shows grid phase voltages, where phase $a$ suffers a $64 \%$ voltage drop during $60 \mathrm{~ms}$ (starting at $t=50 \mathrm{~ms}$ ) with a $\pi / 6 \mathrm{rad}$ (lagging) phase shift. Line currents shown in Fig. 8(b) are balanced at any time with a fast and accurate transient performance with no overshoot. Grid connection shows unity power factor in steady state as shown in Fig. 8(c) and (d).

Under dip condition, $i_{g d}=0 \mathrm{~A}$ and $i_{g q}=-6 \mathrm{~A}$ are observed in Fig. 8(c). Notice the oscillating active and reactive grid power under dip condition shown in Fig. 8(d), as expected, because balanced grid currents and unbalanced grid voltages are present. The average active power delivered to the grid is 0 $\mathrm{W}$ and the average reactive grid power is about 355 VAR. Dclink capacitor voltage balance is achieved all the time as shown in Fig. 8(e).

In steady state, before the voltage sag appearance, the active power extracted from the generator is $416 \mathrm{~W}$ and the active power injected to the grid is $231 \mathrm{~W}$. Therefore the losses in the system are $185 \mathrm{~W}$. The efficiency of the system is quite low, but it is logical as the voltage rating for the switches in the back-to-back NPC shown in Fig. 7 is $1200 \mathrm{~V}$, which presents a significant voltage drop regarding the dc-link voltage $(250 \mathrm{~V})$.

During the dip, the dc-link voltage control is assumed by the generator-side converter. Fig. 9(a) shows the five-level phase-to-phase voltages for the PMSG. As the rotor speed increases during the dip the amount of commutations with the 
(a)

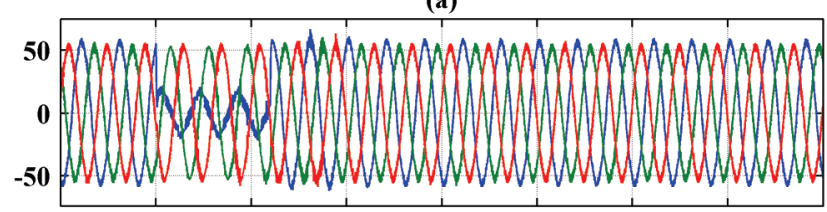

(b)
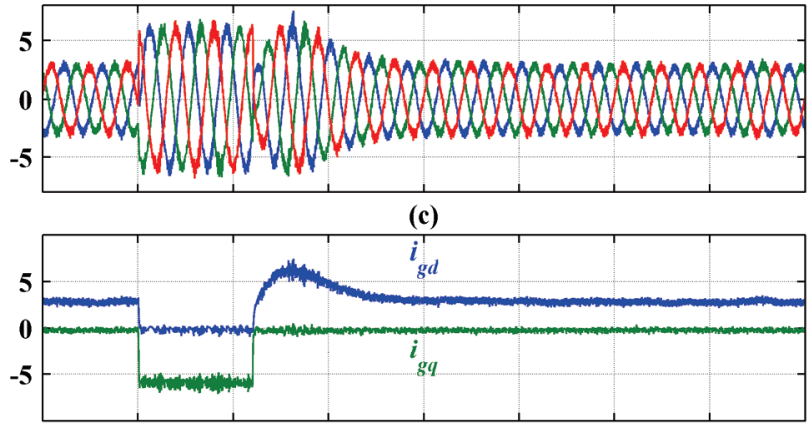

(d)

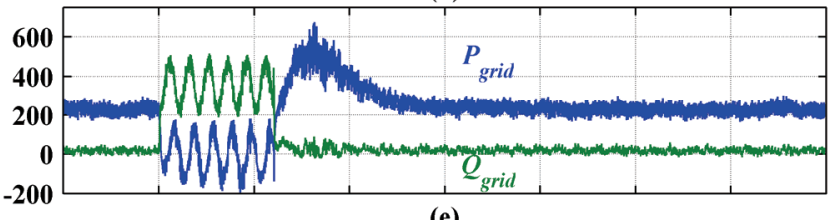

(e)

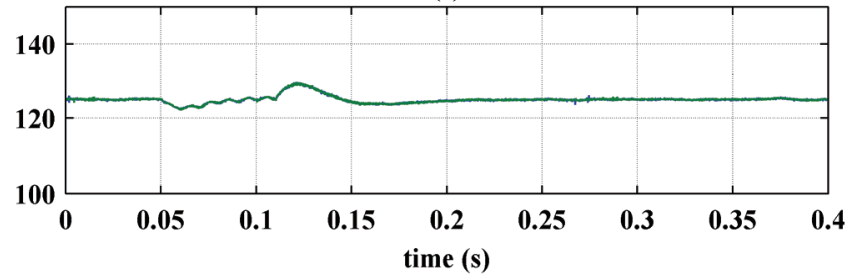

Fig. 8. Experimental grid-side dynamic response during a voltage dip type B with the proposed control. Variables obtained from dSPACE readings. (a) Grid side voltages $\left(v_{a N}, v_{b N}, v_{c N}[\mathrm{~V}]\right)$. (b) Grid $a b c$ currents $\left(i_{a}, i_{b}, i_{c}[\mathrm{~A}]\right)$. (c) Grid $d q$ currents $\left(i_{g d}, i_{g q}[\mathrm{~A}]\right)$. (d) Active and reactive grid power $\left(P_{\text {grid }}[\mathrm{W}]\right.$, $\left.Q_{\text {grid }}[\mathrm{VAR}]\right)$. (e) DC-link capacitor voltages $\left(v_{p}, v_{n}[\mathrm{~V}]\right)$.

higher and lower voltage levels increases leading to an increase in the fundamental component for the generator voltages. Fig. 9(b)-(d) show that the current and the power extracted from the generator do not drop to zero as the generator has to provide the energy for the system losses in order to keep the dc-link voltage constant at its reference value. Therefore, the approach made in this work for the control of the dc-link voltage unbalance is validated. Fig. 9(e) shows the increase of the shaft mechanical speed during the dip and its recovery after dip clearance.

\section{B. Results for commutation reduction strategies.}

The different strategies for reducing the number of commutations, detailed on subsection III.D, have been experimentally verified.

Fig. 10 shows the accumulated number of commutations for the phase $a$ of the grid-side NPC, with no restrictions and allowing only one phase (1F) to commutate every $T_{s}$ between adjacent voltage levels (AL), both results without the term for reducing the number of commutations in the quality function $\left(\lambda_{c S}=0\right)$. The number of commutations reduces significantly with the introduced restrictions. (a)

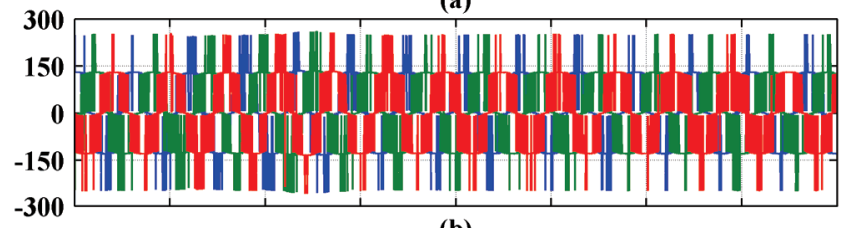

(b)

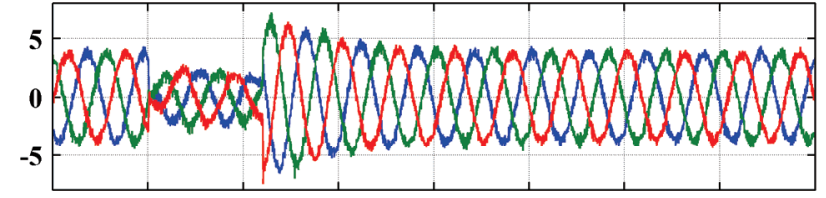

(c)

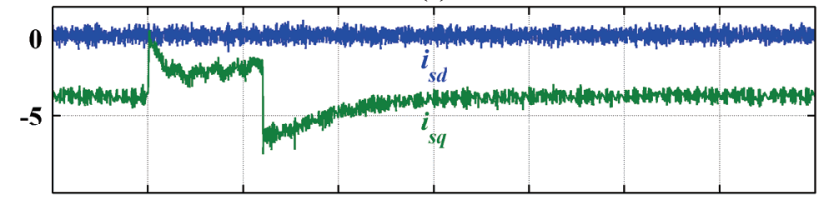

(d)


Fig. 9. Experimental generator-side and dc-link dynamic response during a voltage dip type $\mathrm{B}$ with the proposed control. Variables obtained from dSPACE readings. (a) Generator phase-to-phase voltages ( $\left.v_{u v}, v_{v w}, v_{w u}[\mathrm{~V}]\right)$. (b) Generator $a b c$ currents $\left(i_{u}, i_{v}, i_{w}[\mathrm{~A}]\right.$. (c) Generator $d q$ currents $\left(i_{s d}, i_{s q}\right.$ $[\mathrm{A}])$. (d) Active and reactive generator power $\left(P_{\text {gen }}[\mathrm{W}], Q_{\text {gen }}[\mathrm{VAR}]\right)$. (e) Shaft mechanical speed $\left(\omega_{m}[\mathrm{rpm}]\right)$.

Fig. 11 shows the performance of the system when the weighting coefficients for the commutation reduction term $\lambda_{c S}$ in (21) and $\lambda_{c G}$ in (22) both change from 0 (no commutation reduction) to 0.1 , at $t=200 \mathrm{~ms}$. Notice that the system performance is not affected, despite of the ripples increase in the electrical variables.

As shown in Fig. 11(a)-(b), the active power delivered to the grid increases from $231 \mathrm{~W}$ to $281 \mathrm{~W}$, while the grid reactive power and the active and reactive power extracted from the generator do not change. This is caused because the number of commutations decreases once the commutation reduction term is activated at $t=200 \mathrm{~ms}$, as shown in Table III for steady-state operation. As the power extracted from the generator does not change, but the commutation losses are reduced, there is more available power to be injected to the grid.

Fig. 11(c) shows that the dc-link capacitor voltages are kept balanced at all times, even during the transient when the dclink controller increase the active power given to the grid.

In order to evaluate and compare the different commutation reduction strategies, measurements for the system in steadystate operation have been carried out for an arbitrarily window of $T_{c}=400 \mathrm{~ms}$. The figures of merit for comparing the 


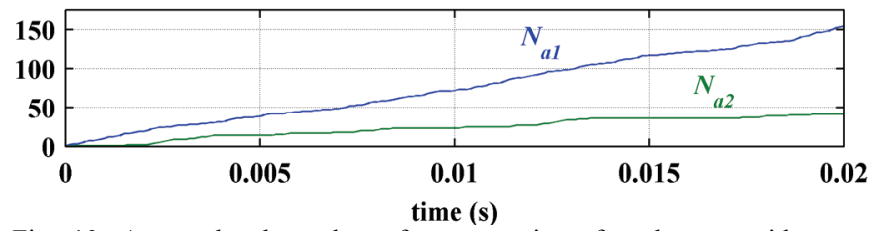

Fig. 10. Accumulated number of commutations for phase $a$ without any restriction $\left(N_{a l}\right)$ and allowing only one phase $(1 \mathrm{~F})$ to commutate between adjacent levels (AL) $\left(N_{a 2}\right)$.
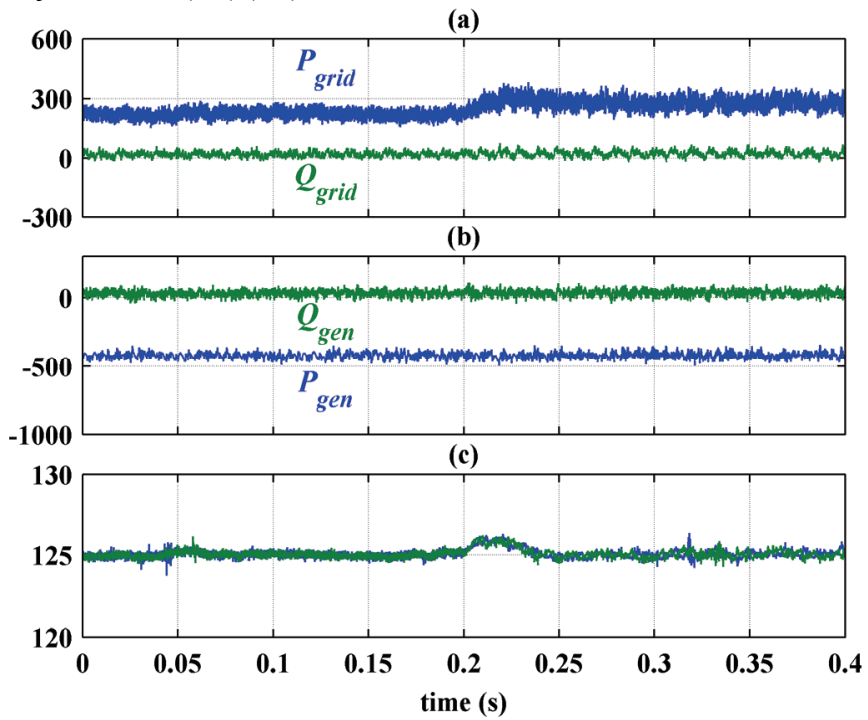

Fig. 11. Effect of including the term (activated at $t=200 \mathrm{~ms}$ ) for reducing the number of commutations in the cost function for both NPC converters. (a) Active and reactive grid power ( $P_{\text {grid }}[\mathrm{W}], Q_{\text {grid }}[\mathrm{VAR}]$. (b) Active and reactive generator power $\left(P_{\text {gen }}[\mathrm{W}], Q_{\text {gen }}[\mathrm{VAR}]\right)$. (c) Dc-link capacitors voltages $\left(v_{p}\right.$, $\left.v_{n}[\mathrm{~V}]\right)$.

(a)

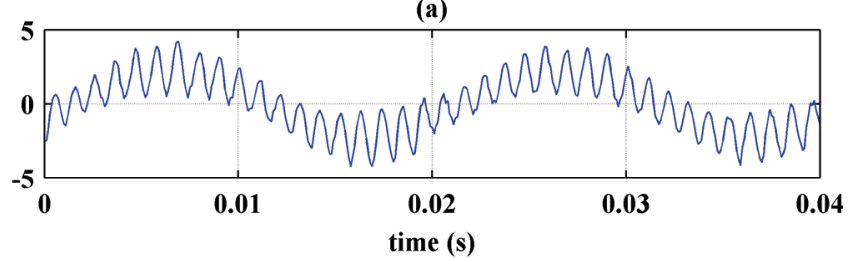

(b)

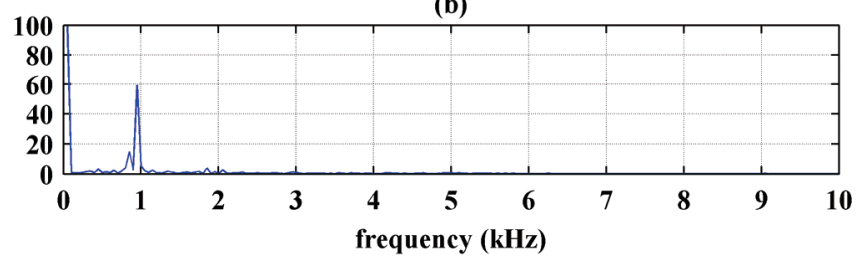

Fig. 12. (a) Line current of one grid-side phase $\left(i_{a}[\mathrm{~A}]\right)$ and (b) its harmonic spectrum amplitude [\%].

different strategies are defined in (24) over the window $T_{c}$ where $\left(P_{G}\right)_{T c}$ is the average steady-state active power injected into the grid; $\left(e_{i}\right)_{G}$ and $\left(e_{i}\right)_{S}$ are the maximum steady state errors (i.e. maximum ripple) in the grid and generator current tracking, respectively; $e_{v o}$ is the maximum steady-state error for the dc-link capacitor voltage balance (i.e. maximum ripple), and $f_{S W a}$ and $f_{S W u}$ are the average switching frequency for phase $a$ and phase $u$, obtained from the accumulative commutations for each phase $N_{a}$ and $N_{u}$. The comparison for the different commutation reduction strategies defined in Table I is shown in Table III.

$$
\begin{gathered}
\left(P_{G}\right)_{T c}=\left|\frac{1}{T_{c}} \int_{0}^{T_{c}} P_{\text {grid }}(t) d t\right| \\
\left(P_{M}\right)_{T c}=\left|\frac{1}{T_{c}} \int_{0}^{T_{c}} P_{\text {gen }}(t) d t\right| \\
(\eta)_{T c}=\frac{\left(P_{G}\right)_{T c}}{\left(P_{M}\right)_{T c}} \cdot 100 \\
\left(e_{i}\right)_{G}=\max \left(\left|i_{\text {dggrid }}^{*}(t)-i_{\text {dgrid }}(t)\right|,\left|i_{\text {qgid }}^{*}(t)-i_{\text {qggid }} t(t)\right|\right) ; t \in\left\{0, T_{c}\right\} \\
\left(e_{i}\right)_{S}=\max \left(\left|i_{\text {dgen }}^{*}(t)-i_{\text {dgen }}(t)\right|,\left|i_{\text {qgen }}^{*}(t)-i_{\text {ggen }} t(t)\right|\right) ; t \in\left\{0, T_{c}\right\} \\
e_{v o}=\max \left(\left|v_{p o}(t)-v_{\text {on }}(t)\right|\right) ; t \in\left\{0, T_{c}\right\} \\
f_{\text {SWa }}=N_{a} / T_{c} ; \quad f_{\text {SWu }}=N_{u} / T_{c}
\end{gathered}
$$

The results in Table III shows that the inclusion of restrictions reduces the number of commutations, thus reducing the commutation losses, increasing the amount of power delivered to the grid whereas the power extracted from the generator is almost the same for all the proposed strategies yielding to an increase in the system efficiency. As the commutations reduce, the switching frequency also reduces, leading to increase the current and dc-link voltage unbalance ripples, even though this commutation reduction techniques do not have an important effect in the dynamic behavior of the system whereas PWM techniques require a reduction in the carrier frequency in order to reduce the converter number of commutations which has a direct effect in the dynamic behavior of the system.

Notice that the system efficiency is very low, it is expected as the power processed by the system and the dc-link voltage is very low compared to the rated current and voltage of the

\begin{tabular}{|c|c|c|c|c|c|c|c|c|}
\hline Type of restriction & $\left(\boldsymbol{P}_{G}\right)_{T c}[\mathbf{W}]$ & $\left(\boldsymbol{P}_{M}\right)_{T c}[\mathbf{W}]$ & $(\eta)_{T c}[\%]$ & $\left|\left(e_{i}\right)_{G}\right|[\mathbf{A}]$ & $\left|\left(e_{i}\right)_{S}\right|[\mathbf{A}]$ & $\left|e_{v o}\right|[\mathrm{V}]$ & $f_{S W a}[\mathrm{kHz}]$ & $f_{S W u}[\mathrm{kHz}]$ \\
\hline No restriction $\& \lambda_{c S}=\lambda_{c G}=0$ & 231 & 417 & 55.59 & 0.84 & 1.22 & 1.50 & 7.52 & 6.62 \\
\hline No restriction $\& \lambda_{c S}=\lambda_{c G}=0.1$ & 281 & 417 & 67.56 & 1.08 & 1.25 & 1.16 & 3.70 & 3.28 \\
\hline $1 \mathrm{~F} \& \lambda_{c S}=\lambda_{c G}=0$ & 280 & 416 & 67.46 & 1.41 & 2.65 & 2.63 & 3.57 & 3.09 \\
\hline $1 \mathrm{~F} \& \lambda_{c S}=\lambda_{c G}=0.1$ & 294 & 419 & 71.37 & 1.96 & 3.43 & 2.85 & 2.62 & 2.04 \\
\hline $1 \mathrm{~F} \& \mathrm{AL} \& \lambda_{c S}=\lambda_{c G}=0$ & 298 & 418 & 70.47 & 1.56 & 2.37 & 2.65 & 2.64 & 2.36 \\
\hline $1 \mathrm{~F} \& \mathrm{AL} \& \lambda_{c S}=\lambda_{c G}=0.1$ & 300 & 416 & 72.27 & 1.94 & 2.08 & 2.90 & 2.36 & 2.04 \\
\hline
\end{tabular}
converter devices, as explained in the previous section.

A further analysis, beyond the scope of this work, should be done to find the best trade-off between commutations reductions and ripples for a specific application.

TABLE III

TEST RESULTS SUMMARY FOR THE DIFFERENT COMMUTATION REDUCTION STRATEGIES. 


\section{Results for an imposed current spectrum.}

The predictive control with imposed current spectrum has been tested by designing a second order band-stop filter with a center frequency $950 \mathrm{~Hz}$. To show the flexibility of the predictive control, the imposed current spectrum has been applied only to the grid-side NPC by using the quality function (23), while the generator-side NPC quality function is kept unchanged (21) with $\lambda_{c S}=0$. Fig. 12 shows the steadystate current for grid phase $a$ and its harmonic spectrum. As expected, the current shows a high $950 \mathrm{~Hz}$ ripple (Fig. 12(a)) with a current spectrum at $950 \mathrm{~Hz}$ (Fig. 12(b)).

\section{CONCLUSIONS}

A model predictive control technique has been proposed for the back-to-back NPC converter applied to a wind energy conversion system, satisfying the requirements demanded for this application, particularly the LVRT compliance.

Different strategies to reduce the number of commutations have been tested. The reduction in the commutations reduces the converter losses reduction but increases the ripple in currents and voltages. Moreover, a stop-band filter has been tested to avoid the spread spectrum inherent in the predictive current control and focus it around a desired frequency.

The flexibility of the predictive control makes it very useful to implement controllers for power converters.

\section{REFERENCES}

[1] Global Wind Energy Council (GWEC), "Global Wind Report. Annual Market Update 2014,” 2015. [Online]. Available: www.gwec.net. [Accessed: 22-Apr-2015].

[2] Red Eléctrica, "The Spanish Electricity System. Summary 2014. Preliminary report.," 2014. [Online]. Available: www.ree.es. [Accessed: 22-Apr-2015].

[3] R. Cardenas, R. Pena, S. Alepuz, and G. Asher, "Overview of Control Systems for the Operation of DFIGs in Wind Energy Applications," IEEE Trans. Ind. Electron., vol. 60, no. 7, pp. 2776-2798, 2013.

[4] M. Liserre, R. Cardenas, M. Molinas, and J. Rodriguez, "Overview of Multi-MW Wind Turbines and Wind Parks," IEEE Trans. Ind. Electron., vol. 58, no. 4, pp. 1081-1095, Apr. 2011.

[5] D. D. Banham-Hall, G. A. Taylor, C. A. Smith, and M. R. Irving, "Towards large-scale direct drive wind turbines with permanent magnet generators and full converters," in IEEE Power and Energy Society General Meeting (PES), 2010, pp. 1-8.

[6] F. Blaabjerg, M. Liserre, and K. Ma, "Power Electronics Converters for Wind Turbine Systems," IEEE Trans. Ind. Appl., vol. 48, no. 2, pp. 708-719, Mar. 2012.

[7] E. ON Netz GmbH, "Grid Code: High and extra high voltage," 2006. [Online]. Available: www.eon-netz.com.

[8] A. Junyent-Ferre, Y. Pipelzadeh, and T. C. Green, "Blending HVDCLink Energy Storage and Offshore Wind Turbine Inertia for Fast Frequency Response," IEEE Trans. Sustain. Energy, vol. PP, no. 99, pp. $1-8,2015$.

[9] European Comission. (EurObserv'ER), "Wind Energy Barometer 2014," Systèmes Solaires - Le J. l'Éolien, no. 16, pp. 46-61, 2015.

[10] Z. Chen, J. M. Guerrero, and F. Blaabjerg, "A Review of the State of the Art of Power Electronics for Wind Turbines," IEEE Trans. Power Electron., vol. 24, no. 8, pp. 1859-1875, Aug. 2009.

[11] M. Popat, B. Wu, and N. R. Zargari, "Fault Ride-Through Capability of Cascaded Current-Source Converter-Based Offshore Wind Farm," IEEE Trans. Sustain. Energy, vol. 4, no. 2, pp. 314-323, Apr. 2013.

[12] S. Kouro, M. Malinowski, K. Gopakumar, J. Pou, L. G. Franquelo, B. Wu, J. Rodriguez, M. A. Pérez, and J. I. Leon, "Recent Advances and Industrial Applications of Multilevel Converters," IEEE Trans. Ind. Electron., vol. 57, no. 8, pp. 2553-2580, Aug. 2010.
[13] J. Rodriguez, S. Bernet, P. K. Steimer, and I. E. Lizama, "A Survey on Neutral-Point-Clamped Inverters," IEEE Trans. Ind. Electron., vol. 57, no. 7, pp. 2219-2230, Jul. 2010.

[14] A. Nabae, I. Takahashi, and H. Akagi, "A New Neutral-Point-Clamped PWM Inverter," IEEE Trans. Ind. Appl., vol. IA-17, no. 5, pp. 518-523, Sep. 1981.

[15] A. Calle-Prado, S. Alepuz, J. Bordonau, J. Nicolas-Apruzzese, P. Cortes, and J. Rodriguez, "Model Predictive Current Control of GridConnected Neutral-Point-Clamped Converters to Meet Low-Voltage Ride-Through Requirements," IEEE Trans. Ind. Electron., vol. 62, no. 3, pp. 1503-1514, 2015.

[16] S. M. Muyeen, R. Takahashi, T. Murata, and J. Tamura, "A Variable Speed Wind Turbine Control Strategy to Meet Wind Farm Grid Code Requirements," IEEE Trans. Power Syst., vol. 25, no. 1, pp. 331-340, Feb. 2010.

[17] A. Faulstich, J. K. Steinke, and F. Wittwer, "Medium voltage converter for permanent magnet wind power generators up to $5 \mathrm{MW}$," in European Conference on Power Electronics and Applications (EPE), 2005, pp. 1-9.

[18] J. Rodriguez, J. S. Lai, and F. Z. Peng, "Multilevel inverters: a survey of topologies, controls, and applications," IEEE Trans. Ind. Electron., vol. 49, no. 4, pp. 724-738, Aug. 2002.

[19] C.-T. Lee, C.-W. Hsu, and P.-T. Cheng, "A Low-Voltage Ride-Through Technique for Grid-Connected Converters of Distributed Energy Resources," IEEE Trans. Ind. Appl., vol. 47, no. 4, pp. 1821-1832, Jul. 2011.

[20] K.-H. Kim, Y.-C. Jeung, D.-C. Lee, and H.-G. Kim, "LVRT Scheme of PMSG Wind Power Systems Based on Feedback Linearization," IEEE Trans. Power Electron., vol. 27, no. 5, pp. 2376-2384, May 2012.

[21] S. Alepuz, A. Calle, S. Busquets-Monge, S. Kouro, and B. Wu, "Use of Stored Energy in PMSG Rotor Inertia for Low-Voltage Ride-Through in Back-to-Back NPC Converter-Based Wind Power Systems," IEEE Trans. Ind. Electron., vol. 60, no. 5, pp. 1787-1796, May 2013.

[22] S. A. Diaz, C. Silva, J. Juliet, and H. A. Miranda, "Indirect sensorless speed control of a PMSG for wind application," in IEEE International Electric Machines and Drives Conference (IEMDC), 2009, pp. 18441850.

[23] J. D. Barros, J. F. A. Silva, and É. G. A. Jesus, "Fast-Predictive Optimal Control of NPC Multilevel Converters," IEEE Trans. Ind. Electron., vol. 60, no. 2, pp. 619-627, Feb. 2013.

[24] V. Yaramasu and B. Wu, "Model Predictive Decoupled Active and Reactive Power Control for High-Power Grid-Connected Four-Level Diode-Clamped Inverters," IEEE Trans. Ind. Electron., vol. 61, no. 7, pp. 3407-3416, Jul. 2014.

[25] J. R. Fischer, S. A. Gonzalez, I. Carugati, M. A. Herran, M. G. Judewicz, and D. O. Carrica, "Robust Predictive Control of Grid-Tied Converters Based on Direct Power Control," IEEE Trans. Power Electron., vol. 29, no. 10, pp. 5634-5643, Oct. 2014.

[26] S. Alepuz, A. Calle, S. Busquets-Monge, J. Nicolas-Apruzzese, and J. Bordonau, "Predictive current control of a back-to-back NPC wind energy conversion system to meet low voltage ride-through requirements," in IEEE Industrial Electronics Conference (IECON), 2013, pp. 5306-5311.

[27] J. Rodriguez, M. P. Kazmierkowski, J. R. Espinoza, P. Zanchetta, H. Abu-Rub, H. A. Young, and C. A. Rojas, "State of the Art of Finite Control Set Model Predictive Control in Power Electronics," IEEE Trans. Ind. Informatics, vol. 9, no. 2, pp. 1003-1016, May 2013.

[28] J. Rodriguez and P. Cortes, Predictive Control of Power Converters and Electrical Drives. Wiley-IEEE Press, 2012.

[29] P. Cortes, M. P. Kazmierkowski, R. M. Kennel, D. E. Quevedo, and J. Rodriguez, "Predictive Control in Power Electronics and Drives," IEEE Trans. Ind. Electron., vol. 55, no. 12, pp. 4312-4324, Dec. 2008.

[30] J. D. Barros and J. F. Silva, "Multilevel Optimal Predictive Dynamic Voltage Restorer," IEEE Trans. Ind. Electron., vol. 57, no. 8, pp. 27472760, Aug. 2010.

[31] S. Kouro, P. Cortes, R. Vargas, U. Ammann, and J. Rodriguez, "Model Predictive Control-A Simple and Powerful Method to Control Power Converters," IEEE Trans. Ind. Electron., vol. 56, no. 6, pp. 1826-1838, Jun. 2009.

[32] R. Vargas, P. Cortes, U. Ammann, J. Rodriguez, and J. Pontt, "Predictive Control of a Three-Phase Neutral-Point-Clamped Inverter," IEEE Trans. Ind. Electron., vol. 54, no. 5, pp. 2697-2705, Oct. 2007.

[33] P. Cortes, J. Rodriguez, D. E. Quevedo, and C. Silva, "Predictive Current Control Strategy With Imposed Load Current Spectrum," IEEE Trans. Power Electron., vol. 23, no. 2, pp. 612-618, Mar. 2008. 
[34] S. A. Verne and M. I. Valla, "Predictive control of a back to back motor drive based on Diode Clamped Multilevel converters," in IEEE Industrial Electronics Conference (IECON), 2010, pp. 2972-2977.

[35] E. J. Fuentes, J. Rodriguez, C. Silva, S. Diaz, and D. E. Quevedo, "Speed control of a permanent magnet synchronous motor using predictive current control," in IEEE International Power Electronics and Motion Control Conference (IPEMC), 2009, pp. 390-395.

[36] D. E. Quevedo, R. P. Aguilera, M. A. Perez, P. Cortes, and R. Lizana, "Model Predictive Control of an AFE Rectifier With Dynamic References," IEEE Trans. Power Electron., vol. 27, no. 7, pp. 31283136, Jul. 2012.

[37] N. Celanovic and D. Boroyevich, "A fast space-vector modulation algorithm for multilevel three-phase converters," IEEE Trans. Ind. Appl., vol. 37, no. 2, pp. 637-641, 2001.

[38] B. Wu, Y. Lang, N. Zargari, and S. Kouro, Power Conversion and Control of Wind Energy Systems. Wiley-IEEE Press, 2011.

[39] S. Hiti, "Modeling and control of three-phase PWM converters," VPEC-Virginia Polytechnic Institute \& State University, 1995.

[40] P. Cortes, J. Rodriguez, C. Silva, and A. Flores, "Delay Compensation in Model Predictive Current Control of a Three-Phase Inverter," IEEE Trans. Ind. Electron., vol. 59, no. 2, pp. 1323-1325, Feb. 2012.

[41] M. Mansor and N. A. Rahim, "Voltage sag detection - A survey," in International Conference for Technical Postgraduates (TECHPOS), 2009, pp. 1-6.

[42] P. Thakur, A. K. Singh, and R. C. Bansal, "Novel way for classification and type detection of voltage sag," IET Gener. Transm. Distrib., vol. 7, no. 4, pp. 398-404, Apr. 2013.

[43] A. K. Sadigh and K. M. Smedley, "Fast voltage sag detection method for single-/three-phase application," in IEEE Applied Power Electronics Conference and Exposition (APEC), 2013, pp. 881-888.

[44] V. Yaramasu, B. Wu, S. Alepuz, and S. Kouro, "Predictive Control for Low Voltage Ride-Through Enhancement of Three-Level Boost and NPC Converter based PMSG Wind Turbine," IEEE Trans. Ind. Electron., vol. PP, no. 99, pp. 1-1, 2014.

[45] G. Saccomando, J. Svensson, and A. Sannino, "Improving voltage disturbance rejection for variable-speed wind turbines," IEEE Trans. Energy Convers., vol. 17, no. 3, pp. 422-428, Sep. 2002.

[46] S. Alepuz, S. Busquets-Monge, J. Bordonau, J. Pontt, C. Silva, and J. Rodriguez, "Fast on-line symmetrical components separation method for synchronization and control purposes in three phase distributed power generation systems.," in European Conference on Power Electronics and Applications (EPE), 2007, pp. 1-10.

[47] S. Alepuz, S. Busquets-Monge, J. Bordonau, J. A. Martinez-Velasco, C. A. Silva, J. Pontt, and J. Rodriguez, "Control Strategies Based on Symmetrical Components for Grid-Connected Converters Under Voltage Dips," IEEE Trans. Ind. Electron., vol. 56, no. 6, pp. 21622173, Jun. 2009.

[48] R. P. Aguilera and D. E. Quevedo, "On stability and performance of finite control set MPC for power converters," in Workshop on Predictive Control of Electrical Drives and Power Electronics (PRECEDE), 2011, pp. 55-62.

[49] T. Geyer, R. P. Aguilera, and D. E. Quevedo, "On the stability and robustness of model predictive direct current control," in IEEE International Conference on Industrial Technology (ICIT), 2013, pp. 374-379.

[50] M. Bollen, Understanding power quality problems: voltage sags and interruptions. IEEE Press, 1999.

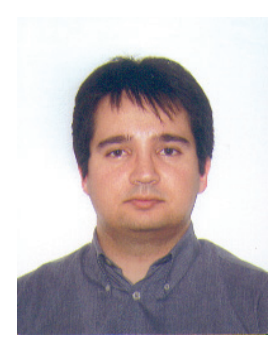

Alejandro Calle-Prado ( $\left.\mathrm{S}^{\prime} 11\right)$ was born in Barcelona, Spain. He received the B. Sc. and M. Sc. degrees in electrical engineering from Universitat Politècnica de Catalunya (UPC), Barcelona, Spain, in 2008 , where he is currently working toward the $\mathrm{Ph}$. D. degree in electrical engineering.

Since 2008, he has been a Researcher in the Power Electronics Research Centre, UPC. His research interests include multilevel power converters applied to renewable energy systems.

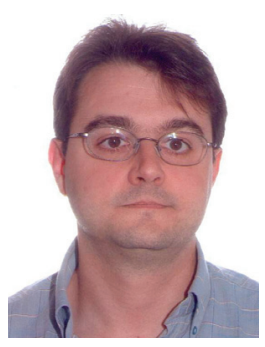

Salvador Alepuz (S'98-M'03-SM'12) was born in Barcelona, Spain. He received the M.Sc. and Ph.D degrees in electrical and electronic engineering from Universitat Politècnica de Catalunya (UPC), Barcelona, Spain, in 1993 and 2004, respectively.

Since 1994, he has been Associate Professor at the Mataró School of Technology, Tecnocampus Mataró-Maresme, Mataró (Barcelona), Spain. From 2006 to 2007, he was with the Departamento de Electrónica, Universidad Técnica Federico Santa María, Chile, developing a postdoctoral research. In 2009, he was a visiting researcher for three months at the Electrical and Computer Engineering Department, Ryerson University, Toronto, Canada. His fields of interest are multilevel conversion and ac power conversion applied to renewable energy systems.

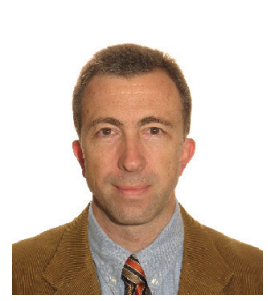

Josep Bordonau (S'87-M'89) received the M.Sc. and the Ph.D. degrees in electrical engineering with honors from Universitat Politècnica de Catalunya (UPC), Barcelona, Spain in 1984 and 1990, respectively.

He has been a Lecturer (1984), an Assistant Professor (1990), and an Associate Professor since 1991, in UPC. Currently, he is Director of the Power Electronics Research Center, UPC, and the Education Director of the Iberia Office in KIC Innoenergy. He is active in more than 30 research projects with international institutions and companies, authoring more than 80 international journal and conference papers (h index 19). His main interest is on ac converters, multilevel technology, renewable energies, energy management sytems, distributed generation systems, smart grids and electric/hybrid vehicles.

Dr. Bordonau is a member of the IEEE Technical Committee in Distributed Generation and Renewable Energy Systems.

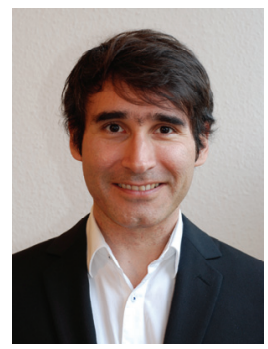

Patricio Cortes (S'05-M'08) received the Engineer and M.Sc. degrees in electronic engineering from the Universidad Técnica Federico Santa María (UTFSM), Valparaíso, Chile, in 2004. He received the Ph.D. degree at the same university in 2008. He also received the Industrial Design degree from the Pontifical Catholic University of Valparaíso in 2006.

From 2008 to 2012 he was a Research Associate at the Electronics Engineering Department, UTFSM. From 2012 to 2014 he was a postdoctoral researcher at the Power Electronic Systems Laboratory at the Swiss Federal Institute of Technology (ETH) Zurich. He is currently with REFU Elektronik GmbH, Germany. He coauthored a book and more than 50 journal and conference papers. His main research interests are modeling and control of power converters.

Dr. Cortes received the Best Paper Award from the IEEE TRANSACTIONS ON INDUSTRIAL ELECTRONICS in 2007.

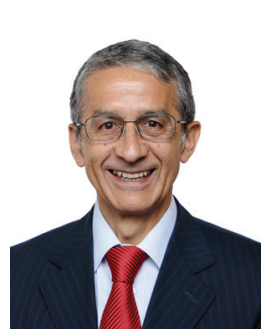

Jose Rodriguez (M'81-SM'94-F'10) received the Engineer degree in electrical engineering from the Universidad Técnica Federico Santa María (UTFSM), Valparaíso, Chile, in 1977 and the Dr.Ing. degree in electrical engineering from the University of Erlangen, Erlangen, Germany, in 1985.

He has been with the Department of Electronics Engineering, UTFSM, since 1977, where he was full Professor and President. Since 2015 he is the President of Universidad Andrés Bello in Santiago, Chile. He has coauthored two books, several book chapters, and more than 400 journal and conference papers. His main research interests include multilevel inverters, new converter topologies, control of power converters, and adjustable-speed drives. He has received a number of best paper awards from journals of the IEEE.

Dr. Rodríguez is member of the Chilean Academy of Engineering. In 2014 he received the National Award of Applied Sciences and Technology from the government of Chile. In 2015 he received the Eugene Mittelmann Award from the Industrial Electronics Society of the IEEE. 